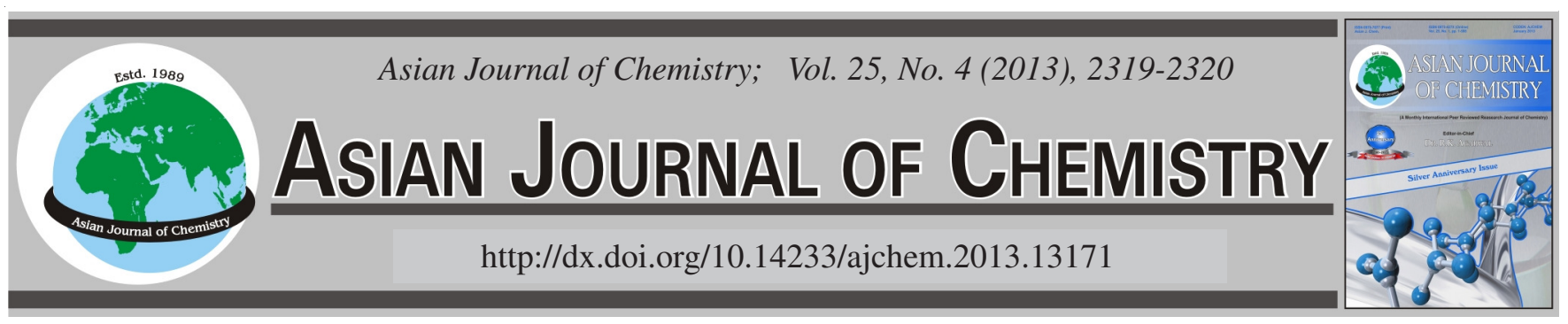

NOTE

\title{
Synthesis and Crystal Structure of Terephthalaldehyde-bis- (thiosemicarbazone)-bis-(dimethyl sulfoxide) Solvate
}

\author{
Wei Su ${ }^{1,2}$, Peiyuan Li ${ }^{1, *}$, Lifeng Liu' ${ }^{2}$, Rui $\mathrm{CHEN}^{1,3,{ }^{*}}$ and Lini HuO ${ }^{1}$
}

${ }^{1}$ College of Pharmacy, Guangxi University of Chinese Medicine, Nanning 530001, P.R. China

${ }^{2}$ College of Chemistry and Life Science, Guangxi Teachers Education University, Nanning 530001, P.R. China

${ }^{3}$ Faculty of Chinese Medicine Science Guangxi University of Chinese Medicine, Nanning 530001 P.R. China

*Corresponding authors: E-mail: lipearpear@yahoo.cn; chrui1980@163.com

\begin{abstract}
A thiosemicarbazone single crystal synthesized with a formula as $\mathrm{C}_{10} \mathrm{H}_{12} \mathrm{~N}_{6} \mathrm{~S}_{2} \cdot 2 \mathrm{C}_{2} \mathrm{H}_{6} \mathrm{OS}$, was synthesized by 1 ,4-phthalaldehyde and 4-methylthiosemicarbazide. The crystal is triclinic, space group P-1 with unit cell parameters: $\mathrm{a}=5.9519(5) \AA, \mathrm{b}=7.4721(7) \AA, \mathrm{c}=$ 12.5450(13), $\alpha=77.348(8)^{\circ}, \beta=78.672(8)^{\circ}, \gamma=79.193(7)^{\circ}, V=527.64(8) \AA^{3}, Z=1, M r=436.63, D c=1.374 \mathrm{~g} / \mathrm{cm}^{3}, \mu=0.471 \mathrm{~mm}^{-1}$ $\mathrm{F}(000)=230, \mathrm{R}=0.0844, \mathrm{wR}=0.2607$ for 1902 reflections with $\mathrm{I}>2 \sigma(\mathrm{I})$.
\end{abstract}

Key Words: Thiosemicarbazone, Terephthalaldehyde, Single crystal, Dimethyl sulfoxide.

Thiosemicarbazones, which possess several donor atoms and can bind to a metal atom both in neutral as well as in anionic forms and have shown a number of bonding modes, has attracted intensive attentions due to its broad spectrum of pharmacological properties, including antitumor, antifungal, antibacterial, antiviral and antimalarial activities ${ }^{1-4}$. Herein, we report a novel terephthalaldehyde bis-(thiosemicarbazone)-bis(dimethyl sulfoxide) solvate single crystal synthesized with a formula $\mathrm{C}_{10} \mathrm{H}_{12} \mathrm{~N}_{6} \mathrm{~S}_{2} \cdot 2 \mathrm{C}_{2} \mathrm{H}_{6} \mathrm{OS}$.

All reagents for synthesis were commercially available and employed as received or purified by standard methods prior to use. Analyses for carbon, hydrogen and nitrogen were performed on a Perkin-Elmer $140{ }^{\circ} \mathrm{C}$ analyzer.

Synthesis: For the synthesis of present compound, $0.134 \mathrm{~g}$ 1,4-phthalaldehyde ( $1 \mathrm{mmol}$ ) and $0.212 \mathrm{~g}$ 4-methylthiosemicarbazide were diluted using $10 \mathrm{~mL}$ mixture solution of ethane and water (1:1). The solution was refluxed and then cooled to room temperature and filtered. The filtration residue was recrystallized using dimethyl sulfoxide/acetone (1:1). Single crystals suitable for X-ray analysis were grown from the dimethyl sulfoxide/ acetone solution by slow evaporation at room temperature in air.

Crystal structure determination: A single crystal of compound with dimensions of $0.21 \mathrm{~mm} \times 0.14 \mathrm{~mm} \times 0.10$ $\mathrm{mm}$ was selected for crystallographic data collection at 293 (2) $\mathrm{K}$ and structure determination on a Bruker SMART CCD$4 \mathrm{~K}$ diffractometer employing graphite-monochromated $\mathrm{MoK}_{\alpha}$ radiation $(\lambda=0.71073 \AA)$. A total of 4031 reflections were collected in the range of $5.66^{\circ} \leq \theta \leq 50.5^{\circ}$, of which 1902 reflections were unique with $\mathrm{R}_{\text {int }}=0.0414$. The data were collected using SMART and reduced by the program SAINT. All the structures were solved by direct methods and refined by full-matrix least squares method on ' $\mathrm{F}^{2}{ }_{\text {obs }}$ ' by using SHELXTL-PC software package. Non-hydrogen atoms were placed in geometrically calculated positions. Hydrogen atoms were added according to theoretical model. The final fullmatrix least-squares refinement including 126 variable parameters for 1902 reflections with I $>2 \sigma$ (I) and converged with unweighted and weighted agreement factors of

$$
\begin{gathered}
\mathrm{R}_{1}=\Sigma\left(|| \mathrm{F}_{0}|-| \mathrm{F}_{\mathrm{C}} \|\right) / \mathrm{S}\left|\mathrm{F}_{0}\right|=0.0844 \\
\text { and } \mathrm{wR}_{2}=\left\{\mathrm{S}\left[\mathrm{w}\left(\mathrm{F}_{0}^{2}-\mathrm{F}_{\mathrm{C}}\right)^{2}\right] / \mathrm{Sw}\left(\mathrm{F}_{0}^{2}\right)^{2}\right\}^{1 / 2}=0.2607
\end{gathered}
$$

where, $\mathrm{w}=1 /\left[\sigma^{2}\left(\mathrm{~F}_{0}^{2}\right)+(0.1014 \mathrm{P})^{2}\right]$ and $\mathrm{P}=\left(\mathrm{F}_{0}^{2}+2 \mathrm{~F}_{\mathrm{C}}^{2}\right) / 3$. The maximum and minimum peaks on the final difference Fourier map are corresponding to 0.766 and $-0.525 \mathrm{e} / \AA^{3}$, respectively.

The selected bond lengths and bond angles are listed in Table-1. Fig. 1 shows the molecular structure of the present compound. Fig. 2 shows the packing diagram of the present compound. The present compound crystallizes in the triclinic system of P-1 space group. The structure of the terephthalaldehyde-bis-(thiosemi-carbazone)-bis-(dimethyl sulfoxide) solvate consists of the thiosemicarbazone and dimethyl sulfoxide. The average $\mathrm{S}-\mathrm{C}$ bond distance in thiosemicarbazone 


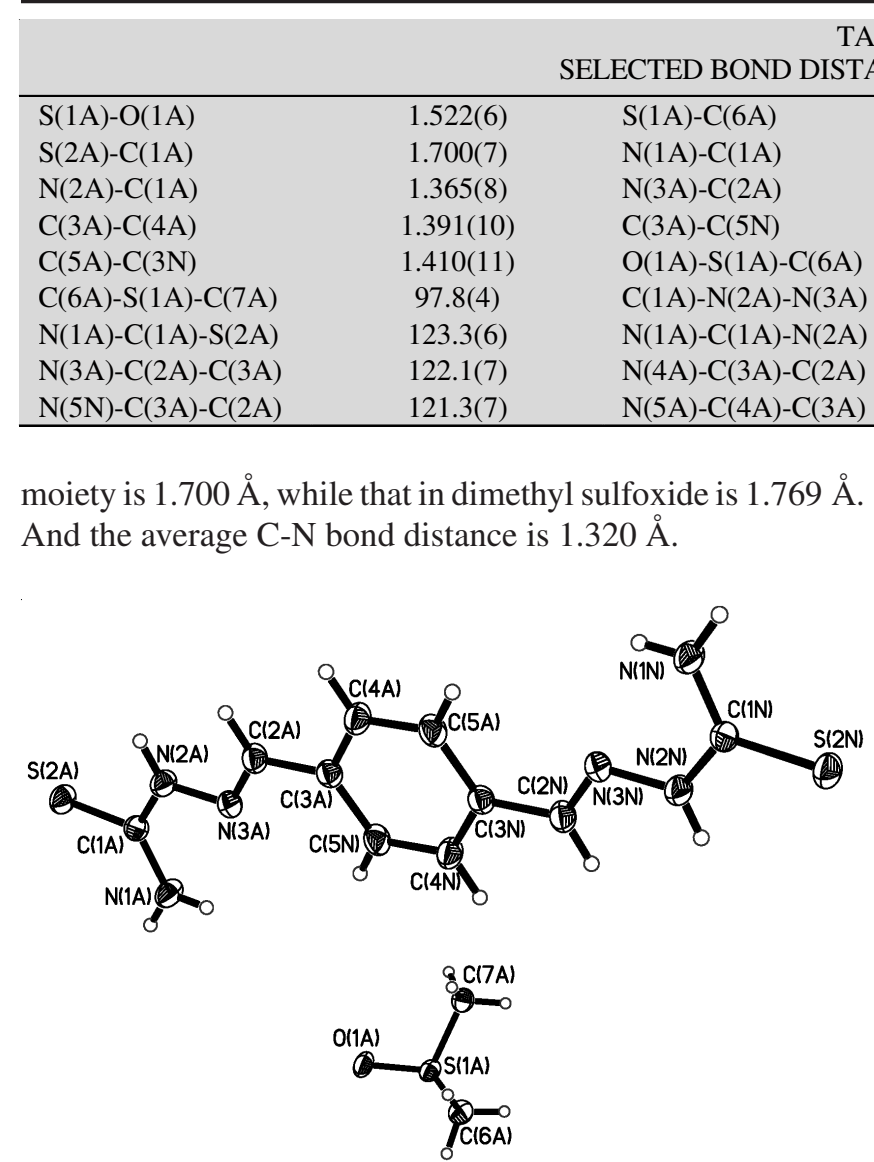

Fig. 1. Molecular structure of the terephthalaldehyde bis-(thiosemicarbazone)-bis-(dimethyl sulfoxide) solvate

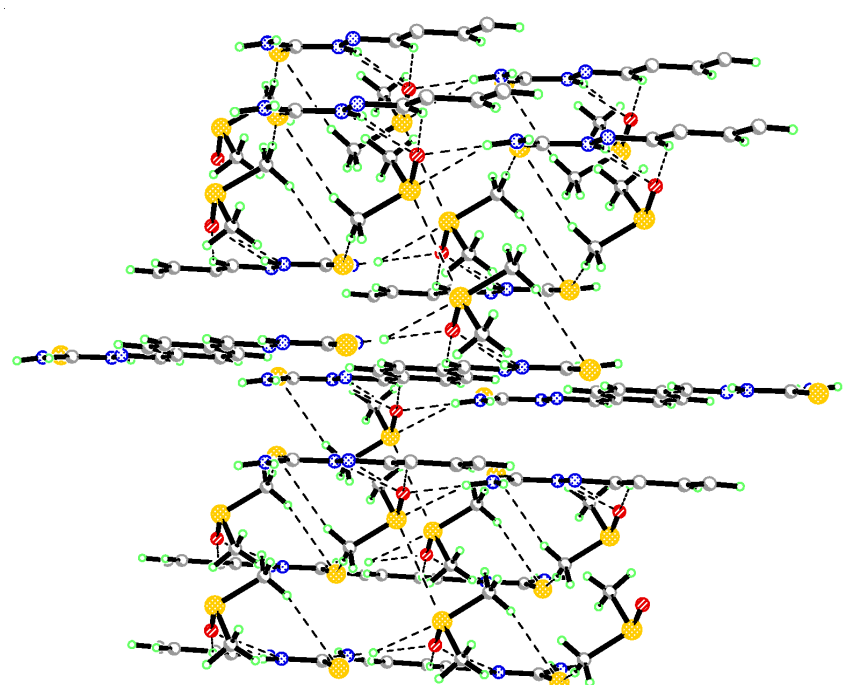

Fig. 2. View of a 3D supramolecular framework of the terephthalaldehyde bis-(thiosemi-carbazone)-bis-(dimethyl sulfoxide) solvate
TABLE-1

\begin{tabular}{ccc} 
& \\
& & \\
$1.769(9)$ & $\mathrm{S}(1 \mathrm{~A})-\mathrm{C}(7 \mathrm{~A})$ & $1.782(8)$ \\
$1.318(9)$ & $\mathrm{N}(2 \mathrm{~A})-\mathrm{N}(3 \mathrm{~A})$ & $1.365(8)$ \\
$1.278(9)$ & $\mathrm{C}(2 \mathrm{~A})-\mathrm{C}(3 \mathrm{~A})$ & $1.459(10)$ \\
$1.410(11)$ & $\mathrm{C}(4 \mathrm{~A})-\mathrm{C}(5 \mathrm{~A})$ & $1.379(10)$ \\
$106.2(4)$ & $\mathrm{O}(1 \mathrm{~A})-\mathrm{S}(1 \mathrm{~A})-\mathrm{C}(7 \mathrm{~A})$ & $106.5(4)$ \\
$119.2(6)$ & $\mathrm{C}(1 \mathrm{~A})-\mathrm{N}(3 \mathrm{~A})-\mathrm{N}(2 \mathrm{~A})$ & $116.6(6)$ \\
$117.3(6)$ & $\mathrm{N}(2 \mathrm{~A})-\mathrm{C}(1 \mathrm{~A})-\mathrm{S}(2 \mathrm{~A})$ & $119.4(5)$ \\
$119.7(7)$ & $\mathrm{N}(4 \mathrm{~A})-\mathrm{C}(3 \mathrm{~A})-\mathrm{C}(5 \mathrm{~N})$ & $119.0(7)$ \\
$121.3(7)$ & $\mathrm{N}(4 \mathrm{~A})-\mathrm{C}(5 \mathrm{~A})-\mathrm{C}(3 \mathrm{~N})$ & $119.7(7)$ \\
\hline
\end{tabular}

\section{Conclusion}

Crystal structure of a novel terephthalaldehyde bis(thiosemicarbazone) bis(dimethyl sulfoxide) solvate has been synthesized and characterized by elemental analysis and $\mathrm{X}$-ray diffraction analysis.

\section{ACKNOWLEDGEMENTS}

This research is supported by the Key Project of Chinese Ministry of Education (Grant No. 2010168), Guangxi Natural Science Foundation (Grant No. 2010GXNSFB013014), National Natural Science Foundation of China (Grant No. 21261005, 51263002) and Scientific Research Fund of Guangxi Provincial Education Department (Grant No. 201106LX273).

\section{REFERENCES}

1. T.S. Lobana, G. Bawa, R.J. Butcher and C.W. Liu, Z. Anorg. Allg. Chem., 635, 355 (2009).

2. R. Pingaew, S. Prachayasittikul and S. Ruchirawat, Molecules, 15, 988 (2010).

3. T.S. Lobana, G. Bawa and R.J. Butcher, Inorg. Chem., 47, 1488 (2008).

4. K. Lee, P. Thanigaimalai, V.K. Sharma, M. Kim, E. Roh, B. Hwang, Y. Kim and S. Jung, Bioorg. Med. Chem. Lett., 20, 6794 (2010). 